cardiovascular or renal chronic disease from primary care or endocrinology clinics. Patients were handed the survey and completed the survey at home, returning it by pre-paid mail. As part of the survey, they completed the quality of life questionnaire EQ-5D-5L.

Results: 2474 patients received the survey, 1618 (65.4\%) returned it (359 with rheumatic disease [mean age 55 years, $63 \%$ women], 341 with IBD [mean age 47 years, $48 \%$ women], 467 with HIV infection [mean age 52 years, $27 \%$ women], 451 with DM [mean age 70 years, $32 \%$ women). Patients with rheumatic diseases more frequently described moderate or severe problems with mobility, self-care and usual activities and reported more pain (table 1). Patients with rheumatic disease and IBD more frequently reported anxiety or depression (table 1). Scores in the Visual Analogic Scale "Your Health Today" (from 0 worst health to 100 best health) were lower in patients with rheumatic diseases (mean score 61.9 [SD 19.5]) than in patients with IBD (68.8 [17.8]), HIV infection (73.3 [19.1]) or DM (67.0 [17.1]), all multiple comparison tests rheumatic disease versus other, $p<0,001)$.

\begin{tabular}{|c|c|c|c|c|c|c|}
\hline & & \begin{tabular}{|c|} 
Rheumatic \\
Disease \\
\end{tabular} & IBD & HIV & DM & $\mathbf{P}$ \\
\hline \multirow{5}{*}{ мовLIту } & I have no problems in walling about & $48.4 \%$ & $74.7 \%$ & $75.3 \%$ & $59.3 \%$ & \multirow{5}{*}{$<0.00$} \\
\hline & I have slight problems in walking about & $27.8 \%$ & $17.3 \%$ & $12.0 \%$ & $21.3 \%$ & \\
\hline & I have moderate problems in walking about & $15.0 \%$ & $6.8 \%$ & $8.5 \%$ & $13.0 \%$ & \\
\hline & I have severe problems in wallking about & $8.5 \%$ & $1.2 \%$ & $3.1 \%$ & $5.8 \%$ & \\
\hline & Soy incapaz de caminar & $0.3 \%$ & $0.0 \%$ & $1.1 \%$ & $0.4 \%$ & \\
\hline \multirow{5}{*}{ SELF-CARE } & I have no problems washing or dressing myself & $70.1 \%$ & $90.8 \%$ & $92.4 \%$ & $86.5 \%$ & \multirow{5}{*}{$<0.00$} \\
\hline & I have slight problems washing or dressing myself & $19.2 \%$ & $7.4 \%$ & $5.5 \%$ & $7.0 \%$ & \\
\hline & I have moderate problems washing or dressing myself & $9.3 \%$ & $1.8 \%$ & $1.3 \%$ & $5.4 \%$ & \\
\hline & I have severe problems washing or dressing myself & $0.8 \%$ & $0.0 \%$ & $0.0 \%$ & $0.7 \%$ & \\
\hline & I am unable to wash or dress myself & $0.6 \%$ & $0.0 \%$ & $0.9 \%$ & $0.4 \%$ & \\
\hline \multirow{5}{*}{ USUAL ACTIVIIIIS } & I have no problems doing my usual activities & $44.6 \%$ & $66.7 \%$ & $77.3 \%$ & $70.1 \%$ & \multirow{5}{*}{$<0.00$} \\
\hline & I have slight problems doing my usual activities & $24.9 \%$ & $17.9 \%$ & $13.8 \%$ & $17.8 \%$ & \\
\hline & I have moderate problems doing my usual activities & $23.4 \%$ & $12.5 \%$ & $6.1 \%$ & $8.3 \%$ & \\
\hline & \begin{tabular}{|l} 
have severe problems doing my usual activities \\
\end{tabular} & $5.1 \%$ & $1.5 \%$ & $2.0 \%$ & $2.7 \%$ & \\
\hline & I am unable to do my usual activities & $2.0 \%$ & $1.5 \%$ & $0.9 \%$ & $1.1 \%$ & \\
\hline \multirow{5}{*}{ PAIN / DISCOMFORT } & I have no pain or discomfort & $9.4 \%$ & $28.6 \%$ & $50.8 \%$ & $31.9 \%$ & \multirow{5}{*}{$<0.001$} \\
\hline & I have slight pain or discomfort & $33.8 \%$ & $42.3 \%$ & $27.5 \%$ & $31.9 \%$ & \\
\hline & I have moderate pain or discomfort & $40.3 \%$ & $23.2 \%$ & $16.5 \%$ & $27.2 \%$ & \\
\hline & I have severe pain or discomfort & $14.5 \%$ & $5.4 \%$ & $4.3 \%$ & $8.1 \%$ & \\
\hline & I have extreme pain or discomfort & $2.0 \%$ & $0.6 \%$ & $0.9 \%$ & $0.9 \%$ & \\
\hline \multirow{5}{*}{ ANXIETY / DEPRESSION } & I am not anxious or depressed & $43.8 \%$ & $44.5 \%$ & $51.2 \%$ & $57.2 \%$ & \multirow{5}{*}{0.042} \\
\hline & I am slightly anxious or depressed & $32.9 \%$ & $35.4 \%$ & $27.6 \%$ & $24.8 \%$ & \\
\hline & I am moderately anxious or depressed & $16.6 \%$ & $15.4 \%$ & $15.0 \%$ & $13.2 \%$ & \\
\hline & I am severely anxious or depressed & $5.4 \%$ & $3.4 \%$ & $5.1 \%$ & $3.6 \%$ & \\
\hline & I am extremely anxious or depressed & $1.2 \%$ & $1.3 \%$ & $1.2 \%$ & $1.2 \%$ & \\
\hline
\end{tabular}

Conclusions: Self-evaluation by patients showed that quality of life of patients with rheumatic diseases (rheumatoid arthritis, spondyloarthritis) is worse that that of patients with IBD, HIV infection or DM. Improving quality of life is an essential goal to achieve in the care of patients with these rheumatic diseases.

Acknowledgements: Funded by Merck Sharp \& Dohme of Spain and endorsed by 4 patients associations (CONARTRITIS: patients with arthritis; ACCU: patients with Crohn's disease and ulcerative colitis; SEISIDA: AIDS multidiscipline group, FEDE: patients with diabetes mellitus).

Disclosure of Interest: None declared

DOI: 10.1136/annrheumdis-2018-eular.2675

\section{FRI0720-HPR THE EFFECT OF OVERWEIGHT ON KNEE PROPRIOCEPTION INPATIENTS WITH KNEE PROSTHESIS DUE TO KNEE OSTEOARTHRITIS}

M. Eymir ${ }^{1}$, B. Ünver ${ }^{1}$, V. Karatosun ${ }^{2} .{ }^{1}$ School of Physical Therapy and Rehabilitation; ${ }^{2}$ Department of Orthopaedics and Traumatology, School of Medicine, Dokuz Eylul University, Izmir, Turkey

Background: Total knee arthroplasty (TKA) has been established as a valuable procedure for the management of patients with disabling knee osteoarthritis, and the rates of elective TKA are increasing steadily each year. Being overweight is a risk factor for osteoarthritis of weight-bearing joints, such as the knee joint. In literature some studies about obesity and lower limb biomechanics found that obesity will change a person's gait model to adapt weight loading. Also it is stated that obese people have to reorganized their neuromuscular function to reduce the total load on the knee joint. Therefore, the ability to reorganize neuromuscular function may be a more insightful risk factor for knee osteoarthritis. There is not any study research on the effect of overweight on knee proprioception in patients with TKA due to osteoarthritis.

Objectives: The aim of this study was to determine the effect of the overweight on knee joint proprioception in patients with TKA due to osteoarthritis.

Methods: The study group consisted of 61 patients, who underwent primary TKA because of arthrosis were stratified by obesity status using pre-operative
BMI. Non-obese ( $n=23$, mean age; $67.60 \pm 8.48$ years) subjects were those with $\mathrm{BMI}<30 \mathrm{~kg} / \mathrm{m} 2$ and obese ( $\mathrm{n}=38$, mean age; $63.81 \pm 9.21$ years) subjects were those with $\mathrm{BMI} \geq 30 \mathrm{~kg} / \mathrm{m} 2$. Patients were evaluated regarding knee proprioception (in knee joint angle $15^{\circ}, 30^{\circ}$ and $60^{\circ}$ ), knee function score (Hospital for Special Surgery (HSS) score), pain (Numeric Pain Rating Scale (NPRS)), knee range of motion, length of hospital stay, the day of knee flexion angle achieved 70 degrees, quality of life (Short-Form 12 Health Survey (SF-12)). Functional activities were evaluated using the lowa Level of Assistance Scale and walking speed was evaluated using the lowa Ambulation Velocity Scale. Patients were evaluated preoperatively and at discharge. All patients underwent the same rehabilitation program.

Results: When the patients' proprioceptive acuity in knee joint angle $30^{\circ}$ were compared between groups, while there were statistically differences preoperatively $(p=0.007)$, there were not differences after surgery $(p>0.05)$. When the proprioceptive acuity measured before and after surgery were compared in knee joint angle $15^{\circ}, 60^{\circ}$, there were not differences ( $p>0.05$ ) between groups. It was determined that; the non-obese group had better results in terms of length of hospital stay, the day of knee flexion angle achieved 70 degrees and both pre-/postoperative knee flexion degree ( $p<0.05$, for all). There were no statistical differences in the pain degree, HSS score, IOWA help level and IOWA walking speed, SF-12 score between groups before and after TKA ( $p>0.05)$.

Conclusions: There were not differences in knee proprioception between groups after surgery $(p>0.05)$. The deficits in joint position sense in patients with TKA may be due to factors other than the BMI level (being overweight). On the other hand, obesity had negative effects on inpatient rehabilitation outcomes following TKA due to osteoarthritis. These results suggest that the rehabilitation afte TKA focused on reducing hospital stay, the day of knee flexion angle achieved 70 degrees and improving knee flexion degree could be important to enhance the potential benefits of the patients' outcomes, and could be important to reduce the payment in rehabilitation hospitals.

Disclosure of Interest: None declared

DOI: 10.1136/annrheumdis-2018-eular.5582

\section{FRI0721-HPR WE ARE IN IT TOGETHER: EXPLORING RHEUMATOLOGY PRACTICE WITH PATIENTS AS RESEARCHER PARTNERS}

O. Gjønnes Tvedten ${ }^{1}$, J. Croker ${ }^{1,2}$, A. Croker ${ }^{2}$, N. Perry ${ }^{1}$, K. Williams ${ }^{1}$, M. Lawrence ${ }^{1} .{ }^{1}$ Dowe St Rheumatology; ${ }^{2}$ University of Newcastle, Tamworth, Australia

Background: Rheumatological conditions are often complex requiring careful history-taking, discussion of options, and plans for treatment and ongoing monitoring. Accordingly, similar to many areas in health, the importance of good communication with patients and with colleagues is well recognised. Issues such as adherence, safety, patient satisfaction and workplace thriving are often cited as supporting evidence for good communication. However communication comes with different intentions (e.g. developed as a one-size-fits-all or personalised to individual situations), in different forms (e.g. verbal, non-verbal, written), occurs within and across different spaces (e.g. face-to-face and technologically enabled) and uses time in different ways (e.g. synchronous and asynchronous, structured or unstructured $)^{1}$. While the literature relating to colleague communication is vast, covering different aspects of communication, literature relating to patient communication tends to focus on one-size-fits-all styles of written communication, such as web resources and printed patient handouts, and verbal and non-verbal communication styles during consultations. We identified scope to contribute to understandings about patient communication by focusing on personalised written communication for patients, as both a product of the consultation and a tool for ongoing dialogue. In taking a patient-centred approach we sought to involve patients as co-researchers and dialogue partners. Together we explored the value of patients' personalised written consultation summaries.

Objectives: The purpose was to (i) to enhance patient communication within a rheumatology practice, and (ii) to develop insights into collaborating with patients in research.

Methods: Collaborative dialogical inquiry provided an appropriate research method for exploring the complex practice of communication, transforming such practice and being authentic to the topic by involving patients. The research team was composed of a rheumatologist, a practice nurse, a medical registrar, a researcher and two patients. Using a lens of appreciative inquiry, data were collected through documenting and recording formal and informal discussions between co-researchers, observing practice and undertaking semi-structured interviews with 20 patients. Each researcher kept a reflective journal about their 